Communications in Physics, Vol. 29, No. 1 (2019), pp. 55-61

DOI:10.15625/0868-3166/29/1/13228

\title{
LIGHT ABSORPTION AND PHOTOLUMINESCENCE QUENCHING PROPERTIES OF BULK HETEROJUNCTION MATERIALS BASED ON THE BLEND OF POLY(N-VINYLCARBAZOLE)/POLY(N-HEXYLTHIOPHENE)
}

\author{
PHAN DINH LONG ${ }^{1}$, NGUYEN NANG DINH ${ }^{2}$ AND NGUYEN PHUONG HOAI NAM ${ }^{2, \dagger}$ \\ ${ }^{1}$ Graduate University of Science and Technology, Vietnam Academy of Science and Technology, \\ 18 Hoang Quoc Viet, Cau Giay, Hanoi, Vietnam \\ ${ }^{2}$ Faculty of Engineering Physics and Nano-Technology, University of Engineering and \\ Technology, Vietnam National University, Hanoi, \\ 144 Xuan Thuy, Cau Giay, Hanoi, Vietnam \\ ${ }^{\dagger} E$-mail: namnph@vnu.edu.vn \\ Received 26 October 2018 \\ Accepted for publication 01 December 2018
}

Published 15 February 2019

\begin{abstract}
The enhancement of light absorption and photoluminescence quenching properties of the bulk heterojunction systems which were fabricated using poly(N-vinylcarbazole) (PVK); poly(N-hexylthiophene) (P3HT) and fullerene derivative 1-(3-methoxycarbonyl) propyl-1-phenyl[6,6] C61 (PCBM) were investigated. The optimized material showed a broad absorption in the region from ultra violet to near infra-red and the photoluminescence quenching higher than $90 \%$. The obtained results provide further insight into photophysics of the heterojunction system and device performance improvement by using this system as an active layer.
\end{abstract}

Keywords: PVK, P3HT, OSC, light absorption, heterojunction, blend polymer.

Classification numbers: 42.25.Bs; 36.20.Fz.

(C)2019 Vietnam Academy of Science and Technology 


\section{INTRODUCTION}

Application of conducting polymers to optoelectronic devices, such as light emitting diodes, and solar cells are of practical significance, because the polymer mixture can be easily prepared and modified by rich chemical procedures to meet optical and electronic requirements. Similar to inorganic solar cells, charge carriers in organic photovoltaic are electrons and holes [?]. Mobility of charge carriers in conducting polymers depend on $\pi$ bonds and super position of quantum mechanical wave function. Photovoltaic devices merely compose of conductive polymers as the active materials have low electron mobility, and thus limit its performance. The performance of organic solar cells is limited by weak absorption in red light, poor charge transport, and low stability, but improvements are possible by optimizing materials and device structures [?]. Recent developments have shown that the use of interpenetrating electron donor-acceptor heterojunctions in a number of materials such as polymer:fullerene $[?, ?, ?]$, polymer:polymer [?], and polymer:nanocrystal [?,?,?] can yield highly efficient photovoltaic conversions. Chirvase et al. [?] find an optimum P3HT:PCBM ratio between 1:1 and 1:0.9 using chloroform as a solvent and these have resulted in good agreement with that published by Pasquier et al. [?]. The other important reasons for the employment of PVK as a host are its favorable film-forming properties, durability at higher temperatures and hole mobility around $10^{-5} \mathrm{~cm}^{2} / \mathrm{Vs}[?, ?, ?, ?]$. The active layers used in organic solar cells have many practical advantages over conventional solar cell materials such as silicon due to its simple methods of fabrication such as spin coating or drop casting.

In this study, the bulk heterojunction of blend conducting polymers and fullerene was fabricated using poly(N-vinylcarbazole) (PVK); poly(N-hexylthiophene) (P3HT) and fullerene derivative 1-(3-methoxycarbonyl) propyl-1-phenyl-[6,6] C61 (PCBM). The blend PVK:P3HT:PCBM enhances light absorption and improves carrier transport behavior. Some kinds of organic solar cells (OSC) have been fabricated with the film of P3HT:PCBM and the blend PVK:P3HT:PCBM as active layers. The current density - voltage $(J-V)$ characteristics of the devices were also studied.

\section{EXPERIMENT}

PVK, P3HT, PCBM were purchased from Aldrich Chemical Co. and used as received. Prior to deposition, the substrates were successively cleaned by using mixture of acetone and alcohol, alcohol and de-ionized water in an ultrasonic bath [?]. The thin films of pristine polymers, blend polymers PVK:P3HT and PVK:P3HT:PCBM with the difference ratios of weight fraction were obtained by mixing the components in chlorobenzene solvent. The solutions at concentration of $13.75 \mathrm{mg} / \mathrm{ml}$ were spin-coated onto the substrates and dried in vacuum $\left(\sim 10^{-3} \mathrm{mbar}\right)$ at $120^{\circ} \mathrm{C}$ for 60 minutes. The thicknesses of the membranes were controlled both by spin speed and by the concentration of the solution. The film's thicknesses were measured using a $\alpha$ step DEKTAK and were found to be around $120 \mathrm{~nm}$. The surface morphologies of the films were observed using "Hitachi" Field Emission Scanning Electron Microscopy (FE-SEM) S-4800. The surface topographies of the polymer thin films were monitored using atomic force microscopy (AFM; advanced scanning probe microscope, XE-100, PSIA) in tapping mode with a silicon cantilever. UV-visible absorption spectra of the films were recorded with UV-Vis SP3000-Nano spectrometer. The photoluminescence (PL) spectra were carried-out by using a FluoroMax-4 spectrophotometer. All the photo physical measurements were performed at room temperature. 
Indium-tin-oxide (ITO) and aluminium (Al) were used as an anode and a cathode, respectively. The structure of the organic solar cells (OSC) were the following: ITO/PEDOT:PSS/P3HT:PCBM/Al and ITO/PEDOT:PSS/PVK:P3HT:PCBM/Al. The ITO glass substrates with a measured sheet resistance of $15 \Omega$ /square (Merck) was used after ultrasonically cleaning in a series of organic solvents (ethanol, methanol, and acetone). The thin films of poly (3,4-ethylenedioxythiophene):poly(styrenesulfonate) (PEDOT:PSS) were spin-casted onto the ITO substrate at $300 \mathrm{rpm}$ for $10 \mathrm{~s}$ and at $3000 \mathrm{rpm}$ for $60 \mathrm{~s}$, consecutively. The $\mathrm{Al}$ cathodes $(100 \mathrm{~nm})$ were thermally evaporated through shadow mask defining an active area of $0.04 \mathrm{~cm}^{2}$. The current- voltage characteristics were measured at room temperature by using Keithley HP 4200 source measurement unit and a calibrated solar simulator (Oriel, Inc.) under AM 1.5G $\left(100 \mathrm{~mW} / \mathrm{cm}^{2}\right)$ irradiation intensity.

\section{RESULTS AND DISCUSSION}

Figure 1 presents the UV-Vis spectra of pristine PVK, P3HT (Fig. 1a) and the blend PVK:P3HT with the difference ratios of weight fraction (Fig. 1b).

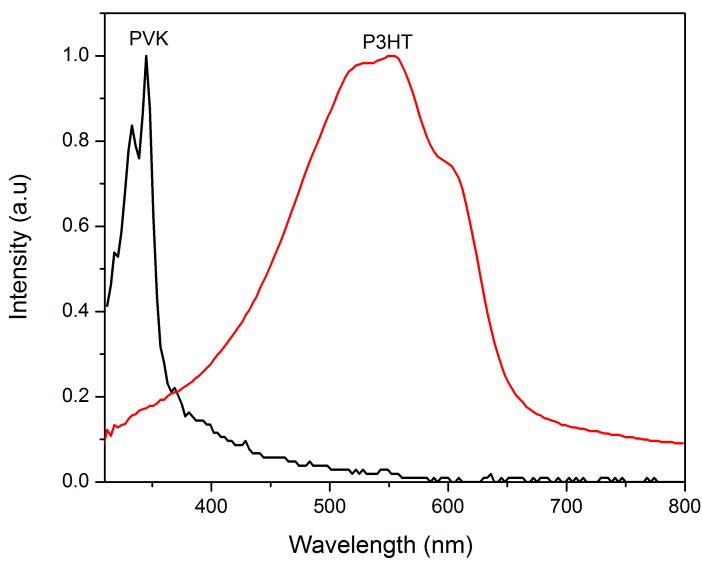

(a)

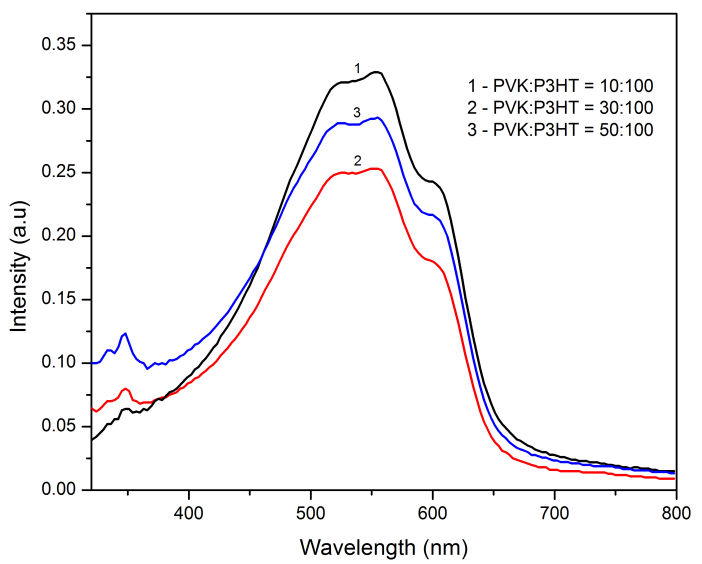

(b)

Fig. 1. (a) Normalized UV-Vis absorption spectra of the pristine polymers and (b) UVVis absorption spectra of the blend polymer films.

From Fig.1a, PVK shows the absorption in the ultra violet wavelength and maximum absorption at $345 \mathrm{~nm}$ due to the transition $\pi-\pi^{*}$ of carbazole groups [?]. P3HT reveals an absorption in the region of 400 to $670 \mathrm{~nm}$ with a maximum absorption at $553 \mathrm{~nm}$. The blend PVK:P3HT shows the absorption in the ultra violet band with maximum at $345 \mathrm{~nm}$ and a broad absorption ranged from 400 to $670 \mathrm{~nm}$ with maximum at $553 \mathrm{~nm}$ corresponding to PVK and P3HT, respectively. It means that there was no chemical interaction between PVK and P3HT molecules. When the content of PVK in the blend increase the UV light absorption intensity of the blend increase and the visible light absorption decrease. At the ratio PVK:P3HT $=1: 2$ (weight fraction), the blend shows the good absorption intensity in UV as well in visible light. This result can be explained by the fact that at the optimal ratio the internal interaction between PVK and P3HT molecules caused 
the optimal distribution of the polymers in the blend. Thus, the light absorption of the blend film is increased. In addition, the blend polymers with the ratio PVK:P3HT equal to 1:2 has advantages over pristine polymers such as $\mathrm{P} 3 \mathrm{HT}$ due to its ultra violet light absorption and thermal stability. This blend with $\mathrm{P} 3 \mathrm{HT}$ as matrix is quite promising for its application in the OSC devices. The bulk heterojunction of the blend PVK:P3HT and PCBM has been fabricated. The PCBM was well known as the acceptor in the heterojunction materials which the conducting polymer acted as the donor $[?, ?]$.

Photoluminescence (PL) quenching is proof that the photo-induced charge transfer in bulk heterojunction film. In Fig. 2, the PL spectra of the blend bulk heterojunction materials with excitation wavelength of $345 \mathrm{~nm}$ (Fig. 2a) and $553 \mathrm{~nm}$ (Fig. 2b) are plotted.

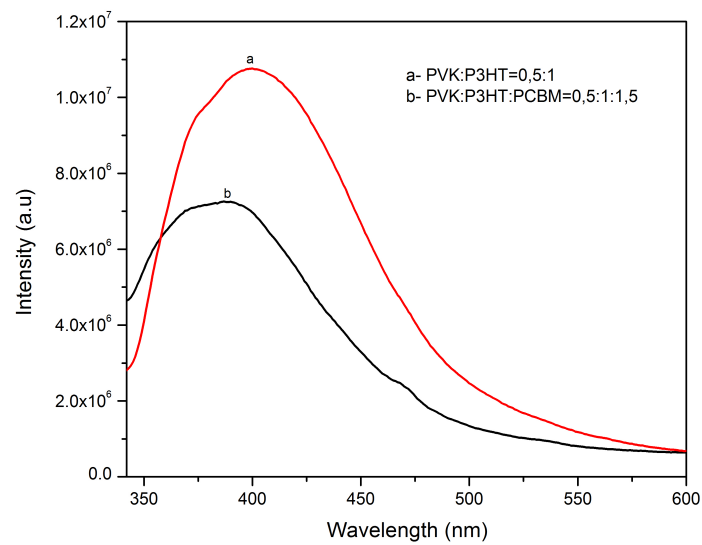

(a)

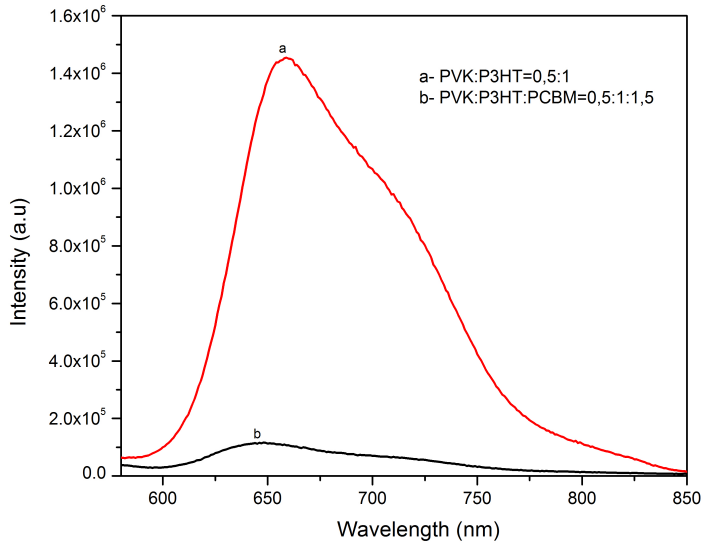

(b)

Fig. 2. Photoluminescence spectra of the blend bulk heterojunction materials films, excited at wavelength $345 \mathrm{~nm}$ (a) and wavelength $553 \mathrm{~nm}$ (b).

In Fig. 2a, we can see that when the blend PVK:P3HT:PCBM $=0.5: 1: 1.5$ (weight fraction) was excited at $345 \mathrm{~nm}$, the PL emission came from PVK due to the absorption light of PVK molecules and its intensity decreased from 10762800 (for the PVK:P3HT film) to 7255740 (for the PVK:P3HT:PCBM film). The photoluminescence quenching was about 33\%. When the PVK:P3HT:PCBM film was excited $553 \mathrm{~nm}$ (Fig. 2b), the PL emission came from P3HT due to the absorption light of P3HT molecules and the intensity decreased from 1454710 (for the PVK:P3HT film) to 116050 (for the PVK:P3HT:PCBM film). The photoluminescence quenching was up to $92 \%$.

This phenomenon can be explained that the PCBM acted as the electron acceptor when it was incorporated with PVK and P3HT which were the donors. As a result, the excitons can be more efficiently separated to electrons and holes, which caused the decrease of the PL intensity. This observation seems to indicate efficient exciton dissociation followed by the rapid photogenerated electrons from PVK and P3HT transfer to the PCBM molecules.

The FE-SEM images of the blend films with the ratio PVK:P3HT $=0.5: 1$ and the blend bulk heterojunction PVK:P3HT:PCBM = 0.5:1:1.5 (weight fraction) films were shown in Fig. 3. 


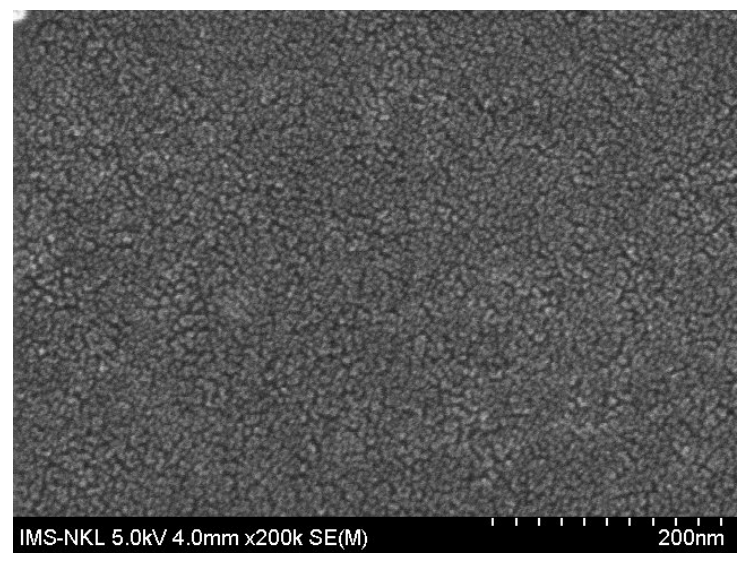

(a)

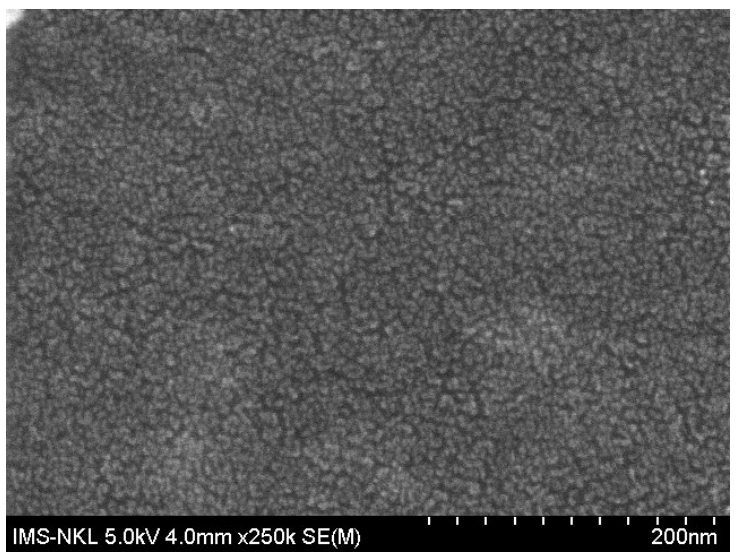

(b)

Fig. 3. FESEM of the surface of PVK:P3HT (a) and PVK:P3HT:PCBM (b) thin films.

From Fig. 3 we can see that the distribution of PVK and P3HT as well as PCBM were perfected. The blend polymer and the bulk heterojunction thin films were in a uniform. The surface's roughness of the blends bulk heterojunction films were $33 \mathrm{~nm}$ and $25 \mathrm{~nm}$ for P3HT:PCBM = $1: 1$ and PVK:P3HT:PCBM = $0.5: 1: 1.5$ (weight fraction), respectively, as shown in Fig. 4. These results imply that the PCBM content promotes fine surface morphology and expects nanophase segregation, which can increase the interfacial area for exciton dissociation between PVK, P3HT and PCBM. In this case, using PCBM has resulted in efficient charge separations at the interface of PVK/PCBM and P3HT/PCBM.

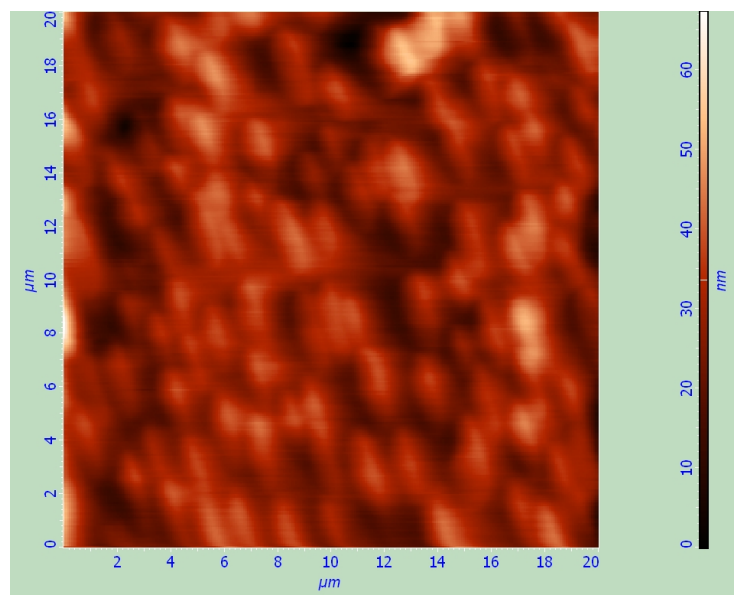

(a)

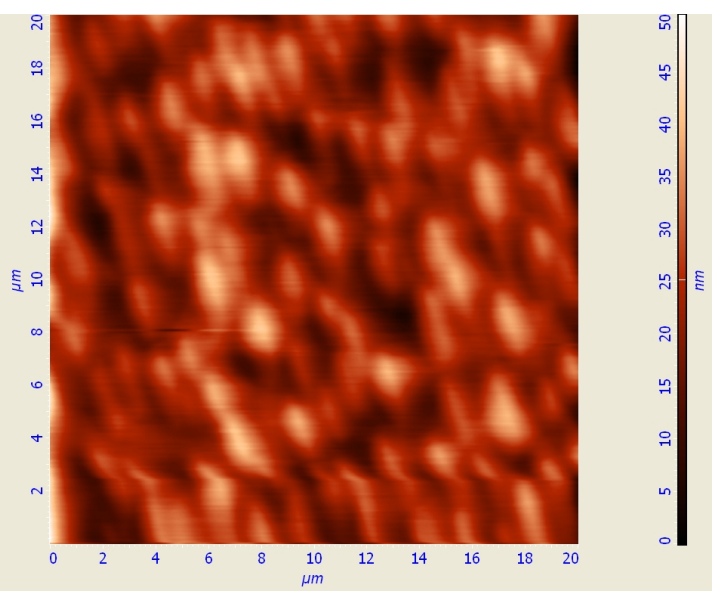

(b)

Fig. 4. AFM images of P3HT:PCBM (a) and PVK:P3HT:PCBM (b) thin films. 
To investigate the photovoltaic properties of the blend PVK:P3HT, the bulk heterojunction solar cells were fabricated with the conventional device configuration ITO/PEDOT-PSS/P3HT: PCBM/LiF/Al and ITO/PEDOT-PSS/PVK:P3HT:PCBM/LiF/Al. The active layers of the devices were deposited by spin-coating under ambient conditions.

Figure 5 shows the current density-voltage $(J-V)$ of the devices containing the active layer P3HT:PCBM = 1:1 and PVK:P3HT:PCBM = 0.5:1:1.5 (weight fraction). The short-circuit current density $\left(J_{s c}\right)$ of the devices ITO/PEDOT-PSS/P3HT:PCBM/LiF/Al) and ITO/PEDOT-PSS/ PVK:P3HT:PCBM/LiF/Al) were $8.06 \mathrm{~mA} / \mathrm{cm}^{2}$ and $10.13 \mathrm{~mA} / \mathrm{cm}^{2}$, respectively. The increase in photocurrent of these devices can attribute to the increase light absorption and efficient charge separation. However, the open circuit voltage $\left(V_{o c}\right)$ of these devices wasn't significantly improved and their fill factor (FF) were 0.61 and 0.48 , respectively. Thus, the power conversion efficiency (PCE) of these devices was remarkably improved from $3.18 \%$ to $3.62 \%$.

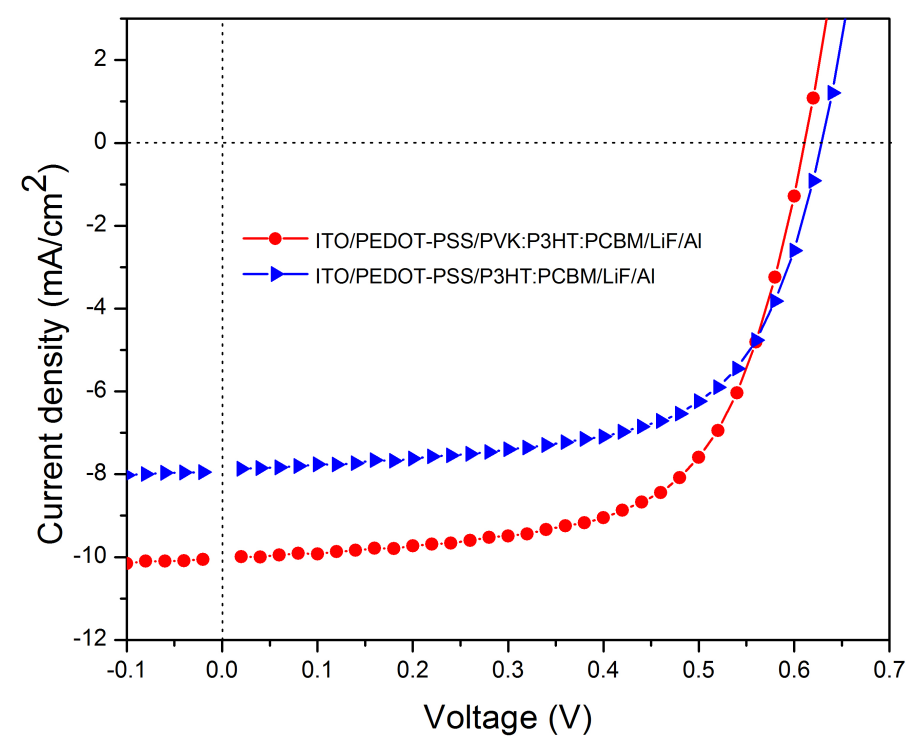

Fig. 5. The current density-voltage $(J-V)$ of the devices.

\section{CONCLUSION}

We have fabricated and investigated the enhancement absorption light and photoluminescence quenching properties of the blend conducting polymers using poly( $\mathrm{N}$-vinylcarbazole) and poly(N-hexylthiophene). The optimized material showed a broad absorption in the region from ultra violet to near infra-red. The blend with the ratio PVK:P3HT:PCBM $=0.5: 1: 1.5$ (weight fraction) enhances light absorption and improves carrier transport behavior. It takes advantages of both durability at higher temperatures and low cost photovoltaic energy conversion and flexibility of the blend conducting polymers PVK:P3HT. The positive outcome of using this kind of material as an active layer for solar cells is clear and the obtained results justified solid improvement of solar cell performance. 


\section{REFERENCES}

[1] V. S. Reddy and A. Dhar, Physica B 405 (2010) 1596.

[2] H. Spanggaard, F. C. Krebs, Sol. Energy Mater. Sol. Cells 83 (2004) 125.

[3] W. Ma, C. Yang, X. Gong, K. Lee, A.J. Heeger, Adv. Funct. Mater. 15 (2005) 1617.

[4] S. E. Shaheen, C. J. Brabec, N. S. Sariciftci, F. Padiner, T. Fromherz, J. C. Hummelen, Appl. Phys. Lett. 78 (2001) 841.

[5] X. Yang, J. Loos, S. C. Veenstra, W. J. H. Verhees, M.M. Wienk, J. M. Kroon, M. A. J. Michels, R. A. J. Janssen, Nano Lett. 5 (2005) 579.

[6] M. Granstrom, K. Petritsch, A. C. Arias, A. Lux, M. R. Andersson, R. H. Friend, Nature 395 (1998) 257.

[7] W. J .E. Beek, M. M. Wienk, M. Kemerink, X. Yang, R.A.J. Janssen, J. Phys. Chem. B, 109 (2005) 9505.

[8] C. Y. Kwong, W. C. H. Choy, A. B. Djurisic, P. C. Chui, K. W. Cheng, W. K. Chan, Nanotechnology 15 (2004) 1156.

[9] Y. Y. Lin, C. W. Chen, J. Chang, T. Y. Lin, I. S. Liu, W. F. Su, Nanotechnology 17 (2006) 1260.

[10] D. Chirvase, J. Parisi, J. C. Hummelen, V. Dyakonov, Nanotechnology 15 (2004) 1317.

[11] A. Du Pasquier, S. Miller, M. Chhowalla, Solar Energy Materials \& Solar Cells 90 (2006) 1828.

[12] T. W. Lee, J. H. Park, O. O. Park, J. Lee and J. C. Kim, Opt. Mater. 30 (2007) 486.

[13] L. Mort and G. Pfister, Electronic properties of polymers, New York: Wiley/Interscience, 1982.

[14] L. O. Palsson, H. L. Vaughan and A. P. Monkman, J. Chem. Phys. 125 (2006) 164701.

[15] N. P. H. Nam, S. W. Cha, B.S. Kim, S.-H. Choi, D. S. Choi, J.-I. Jin, Synth. Met. 130 (2002) 271.

[16] C. W. Tang and S. A. Vanslyke, Appl. Phys. Lett. 51 (1987) 913. 